\title{
VIEWPOINT
}

\section{Nutrition education in the Anthropocene: Toward public and planetary health}

\author{
Jennifer Lynn Wilkins * \\ Syracuse University and Cornell University
}

Submitted February 20, 2020 / Published online May 4, 2020

Citation: Wilkins, J. L. (2020). Nutrition education in the Anthropocene: Toward public

and planetary health. Journal of Agriculture, Food Systems, and Community Development, 9(3),

59-69. https://doi.org/10.5304/jafscd.2020.093.026

Copyright (C) 2020 by the Author. Published by the Lyson Center for Civic Agriculture and Food Systems. Open access under CC-BY license.

\begin{abstract}
Nutrition education has traditionally focused primarily on food and nutrition knowledge, motivations, and skills that facilitate behavior change. This essay argues that while this content remains an essential foundation for nutrition education, is it no longer sufficient. In the Anthropocene-the current distinct geological period during which human activity is the dominant influence on climate and the environment - the goal of nutrition framework is twofold: public health and planetary health. This approach requires that competencies in food systems, agriculture, and policy be included in the education and training of food and nutrition education practitioners and researchers. Academics
\end{abstract}

* Jennifer Lynn Wilkins, President, Society for Nutrition Education and Behavior; Professor of Practice Emeritus, Department of Nutrition and Food Studies, Syracuse University; and Courtesy Professor of Practice, Division of Nutritional Sciences, Cornell University; 115 Orchard Place; Ithaca, NY 14850 USA; +1-607-227-7259; jlwilk01@,syr.edu need to ensure that such competencies are addressed in course content. Advocates need to be vigilant to ensure that sustainability, food systems, and community aspects related to nutrition and diet are incorporated into policy. The relevance of nutrition education will depend upon the degree to which this shift is successful.

\section{Keywords}

Anthropocene, Diet, Food Skills, Health

Outcomes, Nutrition Education

\section{Disclosure}

The views expressed in this reflective essay are those of the author and not necessarily the views of the Society for Nutrition Education and Behavior (SNEB) or its members. The author is the current president of SNEB.

\section{Author Note}

This reflective essay was adapted from the presidential address presented on July 29, 2019, during the business meeting at the $52^{\text {nd }}$ Annual Conference of the Society for Nutrition Education and Behavior in Orlando, Florida. 


\section{Introduction: Urgency}

As president of the Society for Nutrition Education and Behavior (SNEB) - the only professional organization focused solely on nutrition education-I have an ongoing preoccupation with the role of practitioners, academics, researchers, and policy advocates in today's health and ecological contexts. Last summer, as my term as president of SNEB was about to begin, I prepared remarks for the presidential address I would give at the upcoming annual conference. I felt a deep sense of responsibility and opportunity, not to mention urgency. My sense of urgency no doubt was intensified by the heatwave that had settled stubbornly in the U.S. Northeast, where I live, and throughout a large swath of the rest of the country. As I repeatedly pressed "save" to retain my changes, the mercury reached the predicted 97 degrees Fahrenheit and the heat index, thanks to the region's typical humidity, was well on its way to north of 105 degrees.

Simultaneously, across the Atlantic much of Europe was experiencing record high temperatures (Henley, 2019), setting new, all-time national heat records in four countries. So, it was difficult (if not impossible) to ignore the first cause of my feeling of urgency: climate change. Viewing it through the lens of nutrition education, I grew disheartened by how little has been done on a cooperative and global scale to address this issue. This is disheartening, as well, because of steadily mounting evidence and agreement among scientists globally that "it is extremely likely that human influence has been the dominant cause of the observed warming since the mid-20th century" (Intergovernmental Panel on Climate Change, 2013, p. 17). The implication is that changes in human activity are essential to solving this crisis.

Maddeningly, solutions to climate change were at hand when I first learned about the "greenhouse effect" in the 1970s as an undergraduate in the (then) Food and Nutrition Program at Huxley College of the Environment at Western Washington University. I remember well the original Earth Day in 1970 and the excitement and hope surrounding it. But sadly, efforts to achieve meaningful policy change, energy regulations, and controls on greenhouse gas (GHG) emissions that were clearly artic- ulated and attracted strong support, ultimately were not enacted (Rich, 2018). So, here we are.

As David Wallace-Wells makes abundantly clear in Uninhabitable Earth (Wallace-Wells, 2019)_ his no-holds-barred account of what we can expect as climate change progresses-we are in for a whole lot of pain and suffering unless radical changes are made in all aspects of our lives, public policies, and economic systems. According to climate experts, our window of opportunity to avoid the 2-degrees centigrade global temperature increase that scientists believe would spell catastrophe (Intergovernmental Panel on Climate Change, 2018) is closing fast.

My sense of urgency is also exacerbated by what is happening to the natural world overall. In May of 2019, the United Nations released a policymakers' summary of its Global Assessment Report on Biodiversity and Ecosystem Services (Intergovernmental Science-Policy Platform on Biodiversity and Ecosystem Services [PBES], 2019), which is considered to be the most comprehensive assessment of global nature loss to date. The report's bottom line is that one million of Earth's known eight million species are threatened with extinction. The report details how "human actions threaten more species with global extinction now than ever before," and suggests that "around 1 million species already face extinction, many within decades, unless action is taken to reduce the intensity of drivers of biodiversity loss" (IPBES, 2019, pp. 16-17).

In an earlier paper published in Science, Rodolfo Dirzo and colleagues describe what they termed "defaunation" in the Anthropocene and credit humans with the cause: "We live amid a global wave of anthropogenically driven biodiversity loss: species and population extirpations and, critically, declines in local species abundance. Particularly, human impacts on animal biodiversity are an under-recognized form of global environmental change" (Dirzo et al., 2014, p. 401).

These planetary perils_climate change and species extinction—are increasingly seen as intertwined with poor nutritional health globally in all its forms, including obesity, undernutrition, and other dietary risks. The Lancet Commission report from February 2019 claims that three pandemics (obesity, undernutrition, and climate change) "rep- 
resent The Global Syndemic that affects most people in every country and region worldwide" (Swinburn et al., 2019, p. 791). These pandemics constitute a syndemic, or "synergy of epidemics," because they co-occur in time and place, interact with each other to produce complex sequelae, and share common underlying societal drivers" (Swinburn et al., 2019, p. 791). The report suggests that "the major systems driving The Global Syndemic are food and agriculture, transportation, urban design, and land use" (Swinburn et al., 2019, p. 791).

It should be obvious that the lines connecting these drivers to food and nutrition issues - such as access to healthy food, food composition, and the food supply-are short indeed. A growing body of evidence conveys threats to and damage of natural ecosystems, how the poor will suffer the most, and how the current lack of political will to act exacerbates the situation. The question practitioners in the nutrition education space have a responsibility to grapple with is, "What does food and nutrition education look like in the Anthropocene?" - the current distinct geological period during which human activity is the dominant influence on climate and the environment (Anthropocene, n.d.).

\section{A New Framework for Food and Nutrition Education}

Fortunately, practitioners, academics, researchers, and advocates in the field of food and nutrition ed-

Figure 1. Top 10 Global Causes of Death, 2016

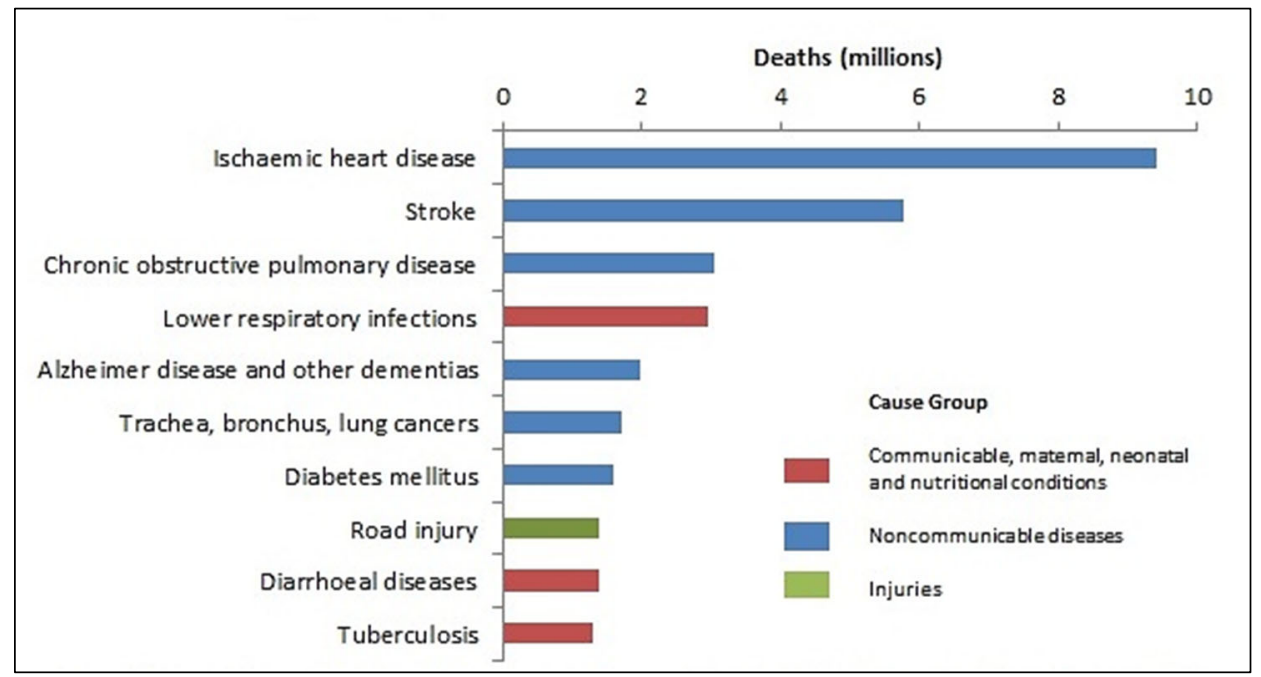

Source: World Health Organization, 2018. ucation already have many tools for addressing current trends and contribute in meaningful ways to solutions. The field of nutrition education is wellpositioned to lead improvements in diet quality, and this action would not only help achieve better health outcomes for individuals and families, but it would also help combat climate change, address syndemics, and put the brakes on the rapid decline of nature. As I reflected with the SNEB membership, while it may seem that we're all doomed, practically every report of our dire environmental situation ends with a message of hope and predicts a reversal of dire trends if we act. The question facing the food and nutrition education field is, will we act? And how will we?

If the nutrition education field is to remain relevant in a time of dramatic ecological change, it needs to lead or at least engage in efforts to promote food-related behaviors that enhance both human and planetary health. After all, food (and therefore eating) depends on a food system that, in turn, depends on natural resources. Human and planetary health are linked, and nutrition education offers a bridge between "after the swallow" considerations (e.g., nutrient utilization and health outcomes) and "before the swallow" considerations (e.g., food supply production methods, extent of processing and amount and type of packaging, mode and length of transportation) reflected in the National Nutrition Monitoring System framework (Liquori, 2001). Achieving optimal health and reducing chronic disease risk through dietary change will always be central reasons for nutrition education. We know that noncommunicable diseases claim thousands of lives annually and respond to and can be prevented, at least in part, through changes in diet (Figure 1). According to the Global Burden of Disease 
(GBD) study, an estimated one in five deaths globallyequivalent to 11 million deaths_-is associated with poor diet, as diet contributes to chronic diseases, particularly heart disease, stroke, cancer, and diabetes in people around the world (GBD 2017 Diet Collaborators, 2019; World Health Organization, 2018).

In the United States, the top 10 causes of death include four that are diet related (Centers for Disease Control and Prevention, 2017).

Further, the fact that diets, especially among Americans, diverge significantly from established federal dietary guidelines (Figure 2), will continue to be a key justification for nutrition education.

In other words, an essential aspect of nutrition education is and will continue to be founded on the integration of evidence related to the links among food, nutrition, diet and health, understanding of determinants of individual behavior change, and environmental supports that encourage and sustain desired behavior change. In this traditional model of nutrition education (Figure 3), the primary outcomes are health and decreased chronic disease risk.

If we come to recognize and appreciate fully that human health and planetary health are inextricably linked, then we need to adopt a more complex nutrition education framework-one that includes evidence related to sustainability, planetary boundaries, and how food choices affect natural ecosystems. We need a framework that reshapes food environments, policy, and systems. Further, the outcomes of our work need to be twofold: improved human health and improved planetary health. Differences in the nutrient content of foods provide the basis for much of what we do in nutri- tion education. But foods also differ in their planetary resource use, or the ecological, social, and economic impacts exerted by the type of food system that produced them. Such considerations, as well as food justice, food sovereignty, and equity, need to be fully integrated into and supported through nutrition education practice. The areas of science and philosophy relevant to nutrition education are expanded when the outcomes extend beyond human health (Figure 4).

The SNEB has developed important tools in this area. Over the past several decades, the society has articulated a set of nutrition education competencies to guide practitioner education, training, and evaluation (SNEB, 2016). In addition to competencies related to foundational knowledge areas of food, nutrition, diet, and health, relevant areas of competency now include food and nutrition policy, and agricultural production and food systems (Figure 5). 
Figure 3. Traditional Model of Nutrition Education focused on Human Health Outcomes

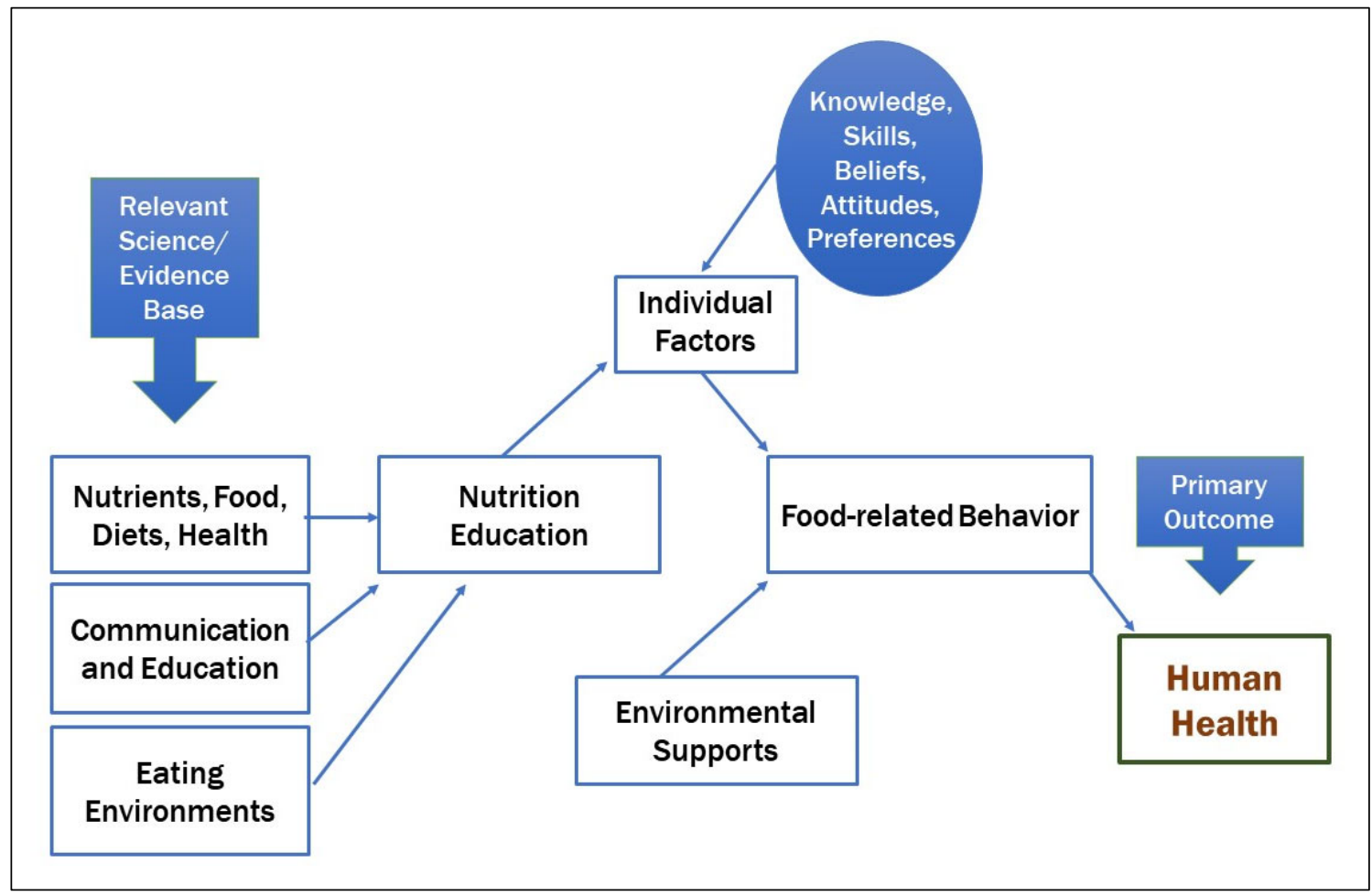

Source: Adapted from Wilkins \& Gillespie, 1996.

Figure 4. Expanded Framework for Nutrition Education

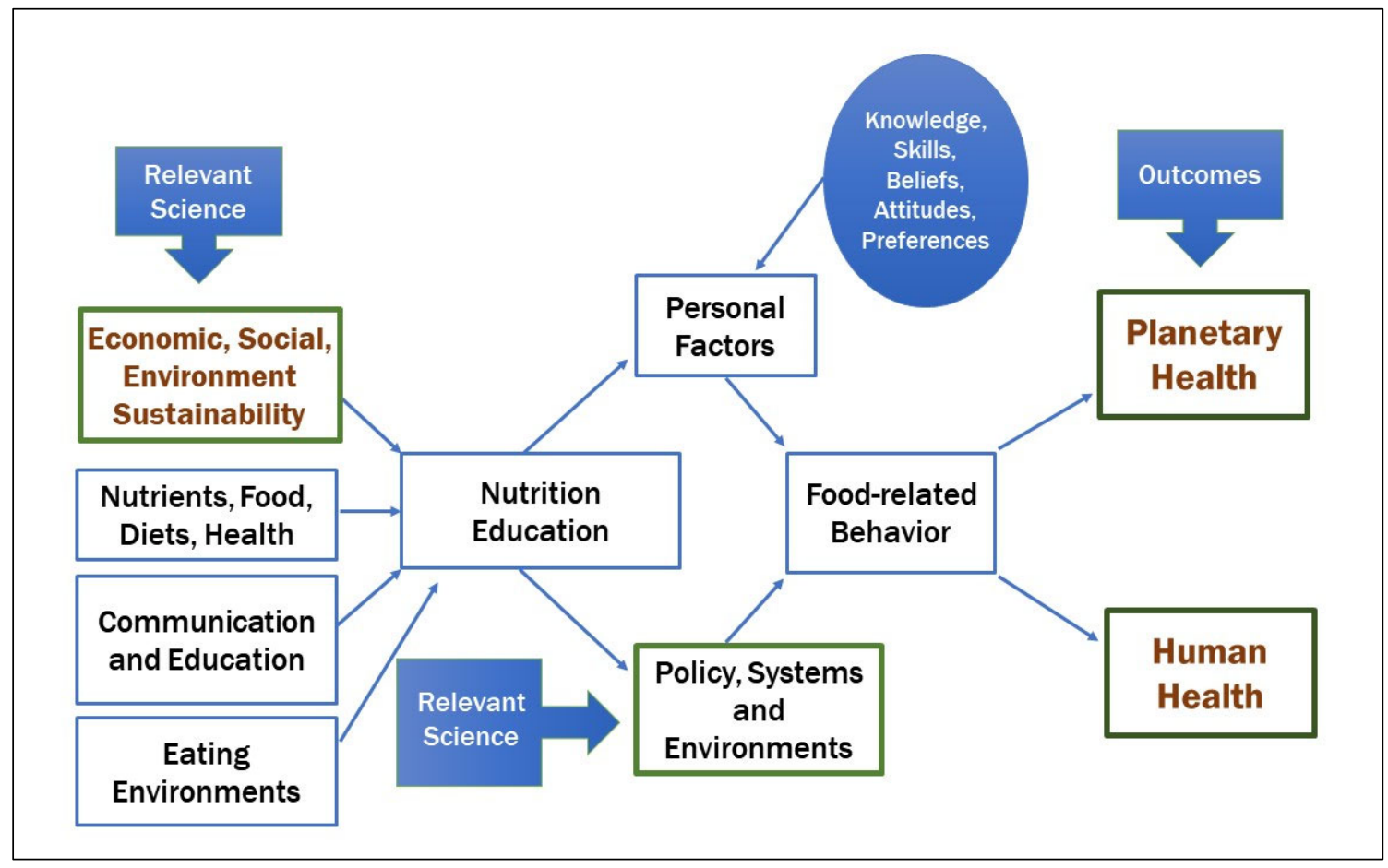

Source: Adapted from Wilkins \& Gillespie, 1996. 
In addition to this broad set of competencies, in the January 2019 issue of its journal, the Journal of Nutrition Education and Behavior, SNEB published its first independent position paper, which focused on the importance of sustainability as a consideration in developing dietary guidance (Rose, Heller, \& Roberto, 2019). This position statement asserts that "environmental sustainability should be an inherent part of dietary guidance, whether working with individuals or groups on their food choices or setting national dietary guidelines" (Rose et al., 2019 , p. 3). This is evidence that SNEB is taking important steps toward integrating public and planetary health.

\section{Rethinking Theory Application}

What else can nutrition education practitioners, academics, researchers, and advocates do? In my view, integrating human and planetary health needs to become the norm in food and nutrition education programs and in evaluating their outcomes. Practitioners and researchers need to ask, "What food knowledge and skills do people need in order to enhance their own health while lowering their environmental impact and enhancing resilience?" And, "How can we heighten planetary health as a motivating factor in food choices and related behavior?"

Part of the answer lies within the theoretical foundation of nutrition education. Several socialpsychological theories of behavior change are commonly employed in planning and evaluating nutrition education interventions. The health belief model, the theory of planned behavior, and the so- cial cognitive theory are among the most frequently used theoretical foundations for designing, implementing, and evaluating nutrition education programs. Each theory proposes how its specific constructs (e.g., perceived benefits, perceived barriers, self-efficacy, norms, perceived threat, etc.) interact to influence a particular behavior of interest. The field of nutrition education practice and related research applies these and other theories to predict and explain a range of food and diet-related behaviors, such as increasing fruit, vegetable, or whole grain intake, increasing variety in the diet, or reducing intake of foods high in sodium and saturated fat.

To see how theory can be applied to encompass issues and concerns beyond health, let's start with a few key constructs, or determinants of behavior change, from familiar behavior change theories. Take for example, "perceived benefits," "perceived risk," and "self-efficacy," three of the core constructs that make up the health belief model. This model asserts "people's readiness to take action or make a health behavior change is influenced by their health beliefs or convictions" (Contento \& Koch, 2020, p. 105). A nutrition edu- 
cation program designed to decrease the risk of cancer or heart disease might focus on increasing vegetable intake as the primary behavior change goal. The program content logically could provide information about the health benefits (addressing "perceived benefits") of consuming a diet rich in fruits and vegetables, as well as evidence related to the risks ("perceived risk") associated with following low fruit and vegetable dietary patterns. To address "self-efficacy," or "the confidence we have that we can perform the behavior" (Contento \& Koch, 2020, p. 106), the nutrition education program might include a food-based component where participants gain experience selecting, preparing, and tasting vegetables.

In such a program, the most proximal, or short-term, outcome might be knowledge change, such as an increased understanding of the health benefits of eating more vegetables and the health risks (in this case, cancer and heart disease) associated with diets poor in vegetables. A midterm outcome could be an actual behavior, such as selection, preparation, and/or consumption of vegetables, being enhanced by an increase in self-efficacy. The long-term outcome would be a decreased risk of disease. This is a common approach for a well-designed nutrition education program focused solely on health outcomes.

How might commonly used theories and related constructs be applied if planetary health and public health outcomes were inextricably linked? The beauty of the theoretical base for most nutrition education programs is that theories can be applied to a wide range of outcomes. In fact, the health belief model was developed originally to help explain the adoption or avoidance of simple health behaviors such as vaccinations or health screenings (Rosenstock, 1974). Nutrition education programs that aimed to simultaneously improve health outcomes and ecological outcomes-protecting groundwater, essential pollinators, and soil microbes or reducing greenhouse gas emissions, for example-could focus on the same general behavior change goal. However, critical qualitative differences would shape program content. For example, when developing program content the program designer would include in "perceived risk" both direct and indirect health and environmental threats. For example, potential health and environmental threats related to agrichemicals used in vegetable production are relevant when discussing "perceived benefits." To address "self-efficacy," the nutrition educator would lead a discussion of the implications of how the vegetables can be sourced (transportation type and distance) and the degree to which the vegetable varieties are adapted to the local area. Once these "before the swallow" considerations start to enter nutrition education program design, the educator's role in policy and food system change to assure that such choices are accessible, available, and affordable begins to come into focus.

\section{Food Skills for Planetary Health}

The 'planetary health' diet proposed in a recent report from the EAT-Lancet Commission on Food, Planet, Health is a laudable attempt to link food choices with environmental impacts (Willett et al., 2019). Globally, and especially in North America, current intake of meat, animal products, and starchy foods in particular, far exceed what the commission concluded is needed to respect planetary boundaries. This assessment of food consumption imbalance might lead nutrition educators to ask, "What food and meal-planning skills do people need to reduce total meat intake and shift to 'lower impact' kinds of meat?" If these were driving questions, the design of nutrition education programs would change.

One implication of integrating planetary and individual health in nutrition education is grounding our practice in community and geographic contexts. What does eating seasonally and choosing from the diversity of local agriculture look like in your area? In my region of the Northeastern U.S., this means grape or rapeseed oils would replace olive oil, and in winter cabbage, carrot slaws, beets, and sprouted seeds would be used in salads. Increasingly, farmers markets offer hearty greens well into winter even in cold climates. Integrating seasonality into nutrition education requires temporal adjustments to foods, recipes, and techniques chosen for food-based programming. Sprouting seeds and legumes is an easily acquired skill, requires minimal investment in equipment, and takes minimal counter space. The yield, in terms of nutrition 
and freshness in the depths of winter, is well worth the effort.

Food and nutrition education is empowering and can help the public address environmental concerns, such as the issue of single-use plastic, that consumers are increasingly bringing to light (Heidbreder, Bablok, Drews, \& Menzel, 2019; North \& Halden, 2013; Thompson, Moore, vom Saal, \& Swan, 2009). As more and more of our food supply is packaged in plastic, increasing evidence is being uncovered detailing the threats this poses to marine life and air quality. Nutrition educators can help individuals identify food products usually available only in plastic that they could make (and might really enjoy making) themselves, such as hummus, pesto, and yogurt. Not only are such household staples easy to make, but the homemade version can be adapted to accommodate family preferences while simultaneously keeping at least some single-use plastic from entering our homes. Nutrition educators have countless opportunities to add such strategies to programs that are otherwise solely health-focused.

To most effectively address diet-related health issues, Carlos A. Monteiro recommends that health and nutrition education professionals focus less on nutrients and more on the type and extent of processing. According to Monteiro, foods can be categorized into four groups according to the degree to which they have been processed (Monteiro et al., 2019). Group 1 foods are "unprocessed or minimally processed," such as a bunch of carrots, raisins, or a steak. Group 2 foods, called "processed culinary foods," include butter, salt, sugar, lard, oils, and flour and are used mostly to enhance the quality and deliciousness of Group 1 foods. Group 3, or "processed foods," includes foods that have been preserved (such as canned, frozen, or dried fruits, vegetables, and beans), pickled, fermented, or salted. Bread, cured and smoked meats, and fish are included in this group. Group 4, or "ultra-processed" items, are unlike any of the others and consist primarily of sugar, oils, salt, and starches. These commodity extractions are transformed and augmented with colors, emulsifiers, flavorings, and occasionally nutrient supplements. Recent research has shown that when people consume a diet high in ultra-processed food, they take in, on average, an extra 500 calories per day and gain more weight than the controls consuming a diet low in ultraprocessed food (Hall et al., 2019). Given the resources required for the extensive processing and packaging characterized by Group 4 foods, they come at substantial ecological costs as well. It is increasingly clear, then, that nutrition education programs need to include strategies to increase knowledge about the health and planetary risks associated with ultra-processed foods, the benefits of avoiding them, and the food-related skills needed to shift diets away from them.

\section{Supporting Food Choices that Enhance Individual and Planetary Health}

Enhancing awareness, knowledge, skills, and confidence at the individual consumer level is not enough. Eaters need supportive food environments in order to exercise their growing interest in health and sustainability. In recent years, policy, systems, and environmental (PSE) approaches to food and nutrition education have emerged as necessary companions to nutrition education focusing on the individual behavior change. In the policy area, there are several opportunities. At the interface of the consumer and the marketplace, food and nutrition educators can identify the kinds of point-of-purchase information that can help consumers make choices in the marketplace based on health and environmental criteria. Beyond calories, ingredients, and the nutrient content of foods, how might food labels provide information such as greenhouse gas emissions associated with foods and production methods? Certainly, nutrition educators have a role to play in developing and designing environmental and social indicators for effective food labeling policy and in conducting research on the effectiveness of related symbols and labels placed on food packages.

As important as such changes in individual food-related behavior are, we cannot ignore the fact that consumers can only choose foods from what is available in the marketplace. Increasingly, food and nutrition educators are engaging in change beyond individual food-related behavior by advocating for food system and environmental change (Rivera et al., 2017). Achieving human and planetary health means that nutrition educators 
need to work at multiple levels - individual, community, systems, and policy - to change both food access and the overarching food system (Calloway, Parks, Bowen, \& Yaroch, 2019).

It should also concern nutrition educators that power in the food system is concentrated in the hands, or the boardrooms, of a small number of corporate giants. As such, the nutrition education field must confront issues of food system power and control. When it comes to the food supply, what is power, and does it matter? I learned recently in Brené Brown's book on daring leadership how the Reverend Martin Luther King, Jr., defined power. In the 1968 speech he delivered to striking sanitation workers in Memphis, he defined power as "the ability to achieve purpose and effect change" (Brown, 2018, p. 95). In addition to being concise, this definition makes clear that power is not inherently good or bad. The issue is how power is wielded. In the case of the food supply, how power is used determines the extent to which health and sustainability are promoted or undermined. Certainly, the current concentration and control among a few giant corporations are not what most would describe as democracy in the food system. Individuals as food citizens have some power to shift control of the food system, but as shapers of policy, nutrition educators can and should wield more.

Since food and nutrition educators have long relied upon and based programs on the Dietary Guidelines for Americans (U.S. Department of Health and Human Services [HHS] \& U.S. Department of Agriculture [USDA], 2015), the ever-present influence of food corporations and the biases and special interests that come along with it are unsettling, at best. Related to the process currently underway to revise the guidelines for the 20202025 edition, the Union of Concerned Scientists reported after the Dietary Guidelines Advisory Committee (DGAC) had been appointed that, "More than half the committee members come with either clear strings to industry-funded research or questionable memberships in industry-funded advocacy groups and foundations" (Jackson, 2019, para. 2). Such conflicts of interest are once again exerting pressure on the Dietary Guidelines process to make sure that the committee does not stray from the strictly diet- and health-focused questions they have been assigned. Despite the substantial increase in scientific evidence related to diet and sustainability, the current DGAC is unlikely to include such areas of research in developing evidencebased dietary guidelines. When the DGAC reviewed the science on sustainability for the 20152020 guidelines, its advice to the DHHS and the USDA was to include guidance on reducing environmental impacts in recommendations on food intake. This advice was ignored and the current $\mathrm{Di}$ etary Guidelines for Americans are silent on the issue of sustainability. If the current DGAC wanted to address questions of sustainability, such as "How do foods differ in their GHG emissions?", by law, it could. The avoidance of such questions, as relevant to dietary advice as they are, most likely reflects either a lack of political will or fear of the consequences of riling up powerful interests, or both. In fairness, addressing all the questions in the official charge was already a tall order. However, reluctance to address questions of sustainability surely is not based on a lack of evidence, since the published research in this area has expanded substantially in the five years since the last DGAC review of the literature (Reinhardt, 2020). What can food and nutrition educators do? As Stephanie Feldstein writes in The Hill, "the 2020-2025 Dietary Guidelines for Americans will have serious consequences for the climate, food security and public health that will extend beyond the next five years" (Feldstein, 2019, para. 4). Nutrition educators, academics, researchers, and advocates need to speak up.

I believe there is great potential for the field of nutrition education to lead the movement toward an integration of human and planetary health. Expertise in food and nutrition and the ability to use that knowledge to empower people to change is needed now more than ever. However, for the field to remain relevant, the changes in food choices we encourage can no longer be focused solely on nutrients, foods, and diets associated with positive health outcomes. Every food choice also impacts the natural, social, and political environments. These impacts need to inform the content of food and nutrition education practice if the field is to play a central role in achieving planetary health. 


\section{Acknowledgments}

The author would like to thank Joan Dye Gussow, Pam Koch, Jasia Steinmetz, and Isobel Contento for their reviews and thoughtful comments on drafts of the speech from which this paper was drawn.

\section{References}

Anthropocene. (n.d.). In Merriam-Webster. Retrieved from https://www.merriam-webster.com/dictionary/Anthropocene Brown, B. (2018). Dare to lead: Brave work. Tough conversations. Whole hearts. New York: Penguin Random House.

Calloway, E. E., Parks, C. A., Bowen, D. J., \& Yaroch, A. L. (2019). Environmental, social, and economic factors related to the intersection of food security, dietary quality, and obesity: An introduction to a special issue of the Translational Behavioral Medicine journal. Translational Behavioral Medicine, 9(5), 823-826. https://doi.org/10.1093/tbm/ibz097

Centers for Disease Control and Prevention. (2017). Leading causes of death. Retrieved from https://www.cdc.gov/nchs/fastats/leading-causes-of-death.htm

Contento, I. R., \& Koch, P. A. (2020). Nutrition education: Linking research, theory, and practice (4th ed.). Burlington, MA: Jones \& Bartlett Learning.

Dirzo, R., Young, H. S., Galetti, M., Ceballos, G., Isaac, N. J. B., \& Collen, B. (2014). Defaunation in the Anthropocene. Science, 345(6195), 401-406. https://doi.org/10.1126/science.1251817

Feldstein, S. (2019, July 11). Trump's Dietary Guidelines Committee shouldn't ignore sustainability. The Hill. Retrieved from https://thehill.com/opinion/energy-environment/452490-trumps-dietary-guidelines-committee-shouldnt-ignoresustainability

Glanz, K. (2001). Current theoretical bases for nutrition intervention and their uses. In A. M. Coultson, C. L. Rock, \& E. Monson (Eds.), Nutrition in the Prevention and Treatment of Disease. New York: Elsevier. https://doi.org/10.1016/B978-012193155-1/50008-8

Glanz, K., \& Bishop, D. B. (2010). The role of behavioral science theory in development and implementation of public health interventions. Annual Review of Public Health, 31, 399-418. https://doi.org/10.1146/annurev.publhealth.012809.103604

Global Burden of Disease 2017 Diet Collaborators. (2019). Health effects of dietary risks in 195 countries, 1990-2017: A systematic analysis for the Global Burden of Disease Study 2017. The Lancet, 393(10184), 1958-1972. https://doi.org/10.1016/S0140-6736(19)30041-8

Hall, K. D., Ayuketah, A., Brychta, R., Cai, H., Cassimatis, T., Chen, K. Y., . . Zhou, M. (2019). Ultra-processed diets cause excess calorie intake and weight gain: An inpatient randomized controlled trial of ad libitum food intake. Cell Metabolism, 30(1), 67-77. https://doi.org/10.1016/j.cmet.2019.05.008

Heidbreder, L. M., Bablok, I., Drews, S., \& Menzel, C. (2019). Tackling the plastic problem: A review on perceptions, behaviors, and interventions. Science of The Total Environment, 668, $1077-1093$. https://doi.org/10.1016/j.scitotenv.2019.02.437

Henley, J. (2019, July 25). All-time temperature records tumble again as heatwave sears Europe. The Guardian. Retrieved from https://www.theguardian.com/world/2019/jul/25/europe-heatwave-paris-forecast-record-hottest-ever-day

Intergovernmental Panel on Climate Change (IPCC). (2007). Summary for policymakers. In IPCC, Climate Change 2007-Mitigation of climate change: Working Group III contribution to the Fourth Assessment Report of the IPCC (pp. 1-24). Cambridge: Cambridge University Press. https://doi.org/10.1017/CBO9780511546013.003

IPCC. (2013): Climate Change 2013: The Physical Science Basis. Contribution of Working Group I to the Fifth Assessment Report of the Intergovernmental Panel on Climate Change. Cambridge University Press, Cambridge, UK, and New York, NY: IPCC.

IPCC. (2018). Summary for policymakers. In V. Masson-Delmotte et al. (Eds.), Global warming of $1.5^{\circ} \mathrm{C}$. An IPCC special report on the impacts of global warming of $1.5^{\circ} \mathrm{C}$ above pre-industrial levels and related global greenhouse gas emission pathways, in the context of strengthening the global response to the threat of climate change, sustainable development, and efforts to eradicate poverty. Geneva: World Meteorological Organization. Retrieved from https://www.ipcc.ch/sr15/chapter/spm/ 
Intergovernmental Science-Policy Platform on Biodiversity and Ecosystem Services (IPBES). (2014). Summary for policymakers. In O. Edenhofer et al. (Eds.), Climate Change 2014: Mitigation of climate change. Contribution of Working Group III to the Fifth Assessment Report of the Intergovernmental Panel on Climate Change. Cambridge, United Kingdom, and New York: Cambridge University Press. Retrieved from https://www.ipcc.ch/site/assets/uploads/2018/02/ipcc wg3 ar5 summary-for-policymakers.pdf

IPBES. (2019). Summary for policymakers of the global assessment report on biodiversity and ecosystem services of the Intergovernmental Science-Policy Platform on Biodiversity and Ecosystem Services. Bonn: IPBES Secretariat. Retrieved from https://ipbes.net/sites/default/files/2020-02/ipbes_global_assessment_report_summary_for_policymakers_en.pdf

Jackson, D. Z. (2019, April 1). Food companies at the table in Trump administration's dietary guidelines committee [Blog post]. Union of Concerned Scientists. Retrieved from https://blog.ucsusa.org/derrick-jackson/trump-administrations-dietary-guidelines-committee

Liquori, T. (2001). Food matters: Changing dimensions of science and practice in the nutrition profession. Journal of Nutrition Education, 33(4), 234-246. https://doi.org/10.1016/S1499-4046(06)60036-5

Monteiro, C. A., Cannon, G., Levy, R. B., Moubarac, J., Louzada, M., Rauber, F., . . Jaime, P. (2019). Ultra-processed foods: What they are and how to identify them. Public Health Nutrition, 22(5), 936-941. https://doi.org/10.1017/S1368980018003762

North, E. J., \& Halden, R. U. (2013). Plastics and environmental health: The road ahead. Reviews on Environmental Health, 28(1), 1-8. https://doi.org/10.1515/reveh-2012-0030

Reinhardt, S. L., Boehm, R., Blackstone, N. T., El-Abbadi, N. H., McNally Brandow, J. S., Taylor, S. F., \& DeLonge, M. S. (2020). Systematic review of dietary patterns and sustainability in the United States. Advances in Nutrition, 0, 1-16. https://doi.org/10.1093/advances/nmaa026

Rich, N. (2018, August 1). Losing earth: The decade we almost stopped climate change. New York Times Magazine. Retrieved from https://www.nytimes.com/interactive/2018/08/01/magazine/climate-change-losing-earth.html

Rivera, R. L., Dunne, J., Maulding, M. K., Wang, Q., Savaiano, D. A., Nickols-Richardson, S. M., \& Eicher-Miller, H. A. (2017). Exploring the association of urban or rural county status and environmental, nutrition- and lifestyle-related resources with the efficacy of SNAP-Ed (Supplemental Nutrition Assistance Program-Education) to improve food security. Public Health Nutrition, 21(5), 957-966. https://doi.org/10.1017/S1368980017003391

Rose, D., Heller, M. C., \& Roberto C. A. (2019). Position of the Society for Nutrition Education and Behavior: The importance of including environmental sustainability in dietary guidance. Journal of Nutrition Education and Behavior, 51(1), 3-15. https://doi.org/10.1016/j.jneb.2018.07.006

Rosenstock, I. M. (1974). Historical origins of the health belief model. Health Education \& Behavior, 2(4), 328-335. https://doi.org/10.1177/109019817400200403

Society for Nutrition Education and Behavior. (2016). Nutrition educator competencies for promoting healthy individuals, communities, and food systems. Retrieved from https://www.sneb.org/clientuploads/directory/Documents/SNEBnutrition-educator-competencies.pdf

Swinburn, B. A., Kraak, V. I., Allender, S., Atkins, V. J., Baker, P. I., Bogard, J. R., . . Dietz, W. H. (2019). The Global Syndemic of obesity, undernutrition, and climate change: The Lancet Commission report. The Lancet, 393(10173), 791-846. https://doi.org/10.1016/S0140-6736(18)32822-8

Thompson, R. C., Moore, C. J., vom Saal, F. S., \& Swan, S. H. (2009). Plastics, the environment and human health: Current consensus and future trends. Philosophical Transactions of the Royal Society of London, Series B, Biological Sciences, 364(1526), 2153-2166. https://doi.org/10.1098/rstb.2009.0053

Wallace-Wells, D. (2019). The uninhabitable Earth: Life after warming. New York: Penguin Random House.

Wilkins, J. L., \& Gillespie, A. H. (1996, July). The Northeast Regional Food Guide. Poster session presented at the 29th annual meeting of the Society for Nutrition Education, St. Louis, Missouri.

Willett, W., Rockström, J., Loken, B., Springmann, M., Lang, T., Vermeulen, S., . . Murray, C. J. L. (2019). Food in the Anthropocene: The EAT-Lancet Commission on healthy diets from sustainable food systems. The Lancet, 393(10170), 447-492. https://doi.org/10.1016/S0140-6736(18)31788-4

World Health Organization (WHO). (2018, May 24). The top 10 causes of death: Fact sheet. Retrieved from https://www.who.int/news-room/fact-sheets/detail/the-top-10-causes-of-death 